\title{
December 1834
}

/19r cont'd/ Monday Dec ${ }^{r} . I^{s t}$.

We are at last come to a new month - which has been ushered in in Paris by very powerful winds from the W. The weather altogether seems to approach nearly to the Nov ${ }^{r}$. weather of England. Went down to the Hotel Dieu this morning. Breschet [did] not come, followed Chomel. Went thence to the Hop ${ }^{1} S^{t}$. Louis. Saw a fine collection of cases, particularly some excellent eczemas \& one of an eruption, which Gibert $c^{\text {ld }}$. not name, tho ${ }^{t}$. most like Lichen Circumscriptus, but which Biett declared to be psoriasis - another also of pityriasis ${ }^{1}$ Versicolor characterised by a nasty scurfy eruption \& yellow color of the part, the front of the chest. Wrote a long letter to the $\mathrm{D}^{\mathrm{r}}$. at Wincanton today. Nothing particular at the "Toucher".

Tuesday Dec $^{r .} 2^{\text {nd }}$.

Went to La Pitié. Saw a case of erysipelas faciei ${ }^{2}$ in Andral's ward - the bowels had not been opened since Saturday - he therefore ordered a Sedlitz powder. ${ }^{3}$ This requires no comment. ${ }^{4}$ Afterwards went to the Hotel Dieu with Breschet. The woman with comp ${ }^{d}$. fracture appears perfectly hectic this morning - tongue is moist but red. B: says she has Gastroenterite - this may be the case, but she certainly has hectic fever. Saw a case of fracture of the leg just above the Malleoli, with dislocation of the foot backwards. I fear Breschet did not treat it properly this however remains to be proved. Was at Sichel's introductory lecture - rather like him, think, I shall attend regularly.

\footnotetext{
${ }^{1}$ Pityriasis: a group of skin diseases marked by irregular patches of a branny or scale-like appearance unaccompanied by redness or inflammation. Pityriasis versicolor chiefly affects the arms, breast and abdomen and can last for years but the itching sensation could be slight. Whilst the condition could be found in individuals of either sex and of any age it was often observed in those who had resided for some time in the tropics. Some cases were attributed to having eaten certain fruits or mushrooms or to wearing flannel next to a sensitive skin. Pityriasis capitis affected very young infants and sometimes the old and the treatment was regular washing with alkaline soap and water. (Hooper, Lexicon, pp. 979-80.)

${ }^{2}$ Erysipelas faciei: facial erysipelas. This was one of the group of diseases called erysipelas, which involved acute inflammation of the skin and subcutaneous tissues and was accompanied by fever. Blisters usually appeared. Also known as St. Anthony's Fire, these diseases could appear on any part of the body, and frequently affected the face. The forms of erysipelas varied in severity and seriousness, leading sometimes to gangrene and even death. The condition, which generally lasted from a week to ten days, was frequently treated by bleeding, cooling saline purgatives and a light vegetable diet. (Hooper, Lexicon, pp. 553-5.)

${ }^{3}$ Misspelling of Seidlitz. Seidlitz powder consisted of dried carbonate of soda and dried tartaric acid. It was a fashionable preparation at the time which when mixed with water effervesced and formed a pleasant aperient, the forerunner of the successful Andrews Liver Salts. Seidlitz powder was named after the saline mineral water found in a village of that name in Bohemia. (Hooper, Lexicon, p. 1114.)

${ }^{4}$ Perhaps he was being sarcastic because after constipation of this duration the patient probably needed more than a single powder. The appropriate dose for "Eau de Seidlitz artificielle faible" (a weak version) is given as " 3 à 4 verres par jour" (three to four glasses a day), and that for the same medicine "forte" as 1 to 2 glasses a day. (Milne-Edwards and Vavasseur, Nouveau formulaire, p. 386.)
} 
$/ 19 \mathrm{v} /$ Wednesday $3^{\text {rd }}$.

Went to $\mathbf{S}^{\mathbf{t}}$. Louis today - some very good cases - particularly one of Lichen Agrius, ${ }^{5}$ which, I am convinced, $w^{\text {ld }}$. have been considered Itch in England. On the arm the eruption was perfectly characteristic of Lepra, but on the hand, especially between the fingers were two or three vesicles, or vesiculo pustules, exactly like those of Itch. Also another excellent case of Porrigo Larvalis ${ }^{6}$ under Alibert - \& Tubercular Syphilis ${ }^{7}$ also under Alibert's care. Case of Greek Elephantiasis ${ }^{8}$ in the arms \& legs - several cases of Eczema, Acne, ${ }^{9} \&$ a multitude of syphilitic ulcerations, tubercules, spots, crusts \&c. Went to Sichel's Dispensary \& entered - fee $15^{\mathrm{F}}$ for 3 months. The cases were not very good today, but one was excellent - traumatic cataract, ${ }^{10}$ apparently situated in the capsule. There had been Iritis \& subsequently adhesion of Iris \& irregularity of pupil. Another case also of Iritis with pustules on the cornea. Had two new additions to our English Society today. Confound them, I wish they had staid [sic] away. ${ }^{11} \operatorname{Ret}^{\mathrm{d}}$. this Evening from my "toucher" miserably tired, have been on my legs all day.

Thursday $4^{\text {th }}$.

Went down to Hotel Dieu, this morning, with Breschet after writing a very long letter to Clifton. Saw a few cases, but nothing of very great interest - came back to my Salon Litteraire. ${ }^{12}$ Afterwards went to Sichel's - saw a few common cases of Catarrhal

\footnotetext{
${ }^{5}$ Lichen Agrius, which could follow imprudent exposure to cold, was an acute but non-recurring form of the disorder heralded by nausea, pain in the abdomen and limbs as well as headache and shivering. These symptoms could last for ten days during which the papulae, which tended to become pustular, appeared in vivid red, painful patches. (Hooper, Lexicon, pp. 770-3.)

${ }^{6}$ Porrigo: described as ringworm when on the scalp, was a contagious condition unaccompanied by fever. It mainly appeared on the scalp but it could affect the face and even spread down to the upper regions of the body and arms. Willan described six varieties, of which the form larvalis, seen as confined to infants, appeared first on the forehead and cheeks. Despite the scratching and bursting of the pustules, which could continue to reappear until teething was under way, there was no scarring when the disease ended. It could be treated with mercurial purgatives and gentle tonics. (Hooper, Lexicon, pp. 1001-5.)

${ }^{7}$ Tubercular syphilis: correctly "tuberculous syphilis". In the early nineteenth century, in the absence of knowledge of bacteria or of cellular events in the disease process there was a concept of all-pervasive morbific states referred to as "diatheses". This indicated a predisposition to certain diseases of the skin, scrofulous, leprous, syphilitic conditions, rheumatic states and nervous conditions. (Crissey and Parish, Dermatology and syphilology, p. 148.) Thus a case of syphilis could also manifest symptoms of tuberculosis.

${ }^{8}$ According to Larousse médical (p. 383), elephantiasis as described by the Greeks was a variety of leprosy more usually called elephantiasis italica or pellagra because it was peculiarly prevalent in certain Italian districts such as Milan and Padua, and could be fatal. Its onset and symptoms were different from elephantiasis, although the skin also became hard and scaly; sometimes the skin condition disappeared seasonally. (Hooper, Lexicon, p. 533.)

${ }^{9}$ Acne: a condition in which papulae or pimples appear on the forehead and chin and sometimes on the neck, shoulders and breast. It was seen as due to an obstruction of the free passage of sebaceous matter from the follicles to the surface of the skin which led to hardening, distension and inflammation of the follicles. Then as now it usually manifested itself from puberty to about twenty-five years of age and was more common in young men than in women. It did not impair general health and medicines were seldom used. (Hooper, Lexicon, pp. 35-6.)

${ }^{10}$ Traumatic cataract: rapid impairment of vision due to cataract. In many cases cataracts develop only gradually. Capsular cataract is due to an opacity of the capsule, preventing the rays of light passing to the retina, an extension of the optic nerve. (Lexicon, p. 333.)

${ }^{11}$ Foreign students studying in Paris formed their own meeting groups or societies for social reasons and to discuss their work. The diarist is therefore here probably referring to an English medical student society and one wonders about the source of his irritation.

${ }^{12}$ Salon Litteraire: properly, salon littéraire, reading room. See January 1, note 2.
} 


\section{4-5 December 1834}

Conjunctivitis, ${ }^{13}$ one or two of Staphyloma, ${ }^{14}$ \& Amaurosis \& one of what, he termed, Conical Cornea,${ }^{15}$ but which by no means answered the description given of this disease, by English Authors. ${ }^{16}$ I fancy I improve every day in the conversational part of the French language - at least, I hope so.

\section{Friday $5^{\text {th }}$.}

Went to the Hotel Dieu, this morning, with Sanson. He had a capital case of fracture of the thigh, about the middle. He employed a new apparatus, two long splints, one to extend from the Crista Iliii $^{17}$ to three or four inches beyond the foot - the other from the groin to the same distance beyond the foot. These were $/ 20 \mathrm{r} /$ joined together, below by a cross bar of wood. Two tapes fastened by means of a roller round the ankle, enabled the operator to keep up as much extension, as he pleased. The upper extremities of the splints were hollowed to allow of the fixture of bands to prevent their slipping. He had also a case of dislocation of the scapular end of the clavicle ${ }^{18}$ - being in a hurry, he did not dress [it], but left his interne to apply the proper bandage. This is one of the bad effects of having too many patients under the care of one Surgeon. The accident is easily recognised by the prominence of the $\operatorname{ext}^{\mathrm{y}}$. of the bone - but the latter is with consid ${ }^{1}$. difficulty repressed[?] into its proper place. I wished particularly to see the bandage by which they proposed retaining it there. Probably I shall have an opportunity, tomorrow morning. His eye cases are not worth seeing, as there is so great a crowd of students, \& the light is immediately removed, when Sanson leaves the bed, ${ }^{19}$ that one never has an opportunity of looking at them. Srom the Hotel Dieu, went to La Pitié. Andral had a case in which Bruit de $\mathrm{Scie}^{20}$ was heard in the carotid, apparently from a narrowing of the artery, produced by [the] pressure of an enlarged thyroid gland. Went to Sichell's [sic], at one - he had some capital cases. If it does nothing more, it will give a man considerable tact in the examination of the diseases of the eye, \& in that manner assist, if in no other, to make him a tolerably good oculist.

\footnotetext{
${ }^{13}$ Catarrhal Conjunctivitis: cases of inflammation of the conjunctiva over the front of the eyeball, with a catarrhal discharge.

${ }^{14}$ Staphyloma: disease of the eyeball in which the cornea loses its natural transparency, rises above the level of the eye and successively projects, somewhat grapelike, beyond the eyelids and even onto the cheek. The disease, which may affect the whole of the cornea, is accompanied by total loss of sight. Surgery to remove all the adventitious growths is required, together with detergent lotions and such caustic application as can be used with safety on the eye. Staphyloma can also affect other membranes in the eyeball such as the iris, when it is called staphyloma iridis. (Hooper, Lexicon, p. 1154.)

${ }^{15}$ Conical Cornea: Hooper describes this condition, citing two cases, each with one eye affected and in which the figure of the cornea was "very remarkable". When viewed laterally the apex resembled a piece of solid crystal and viewed from the front had a transparent sparkling appearance, which prevented the pupil and iris from being distinctly seen. One lady of at least thirty years old could see distinctly, but with considerable effort, only small objects held towards the temporal angle of the eye at about an inch away and only within a limited sphere of vision. (Lexicon, pp. 347-8.)

${ }^{16}$ For a comprehensive review of conditions of the eye and the publications of a range of authors on treatments of these conditions, see the entry on 'Ophthalmy' in Cooper, Dictionary of practical surgery, pp. 865-912.

${ }^{17}$ Crista Ilii: part of pelvic area in the hip region.

${ }^{18}$ Clavicle: the collar bone.

${ }^{19}$ It would seem that during the surgeon's ward round the interne carried a lamp from patient to patient, especially when eye conditions were being examined.

${ }^{20}$ Bruit de Scie: grating sound like that made by a saw or file. This is one of the many instances where the diarist uses the French term for a symptom.
} 
Saturday $6^{\text {th }}$.

Went to the Hotel Dieu, heard Sanson's Clinique - can't say I was much benefitted by it. Saw his outpatients, \& then went round with Breschet - confound this little fat brute. He kept me waiting for him, nearly half an hour. Saw him pare the edges of an old ulcer on the heel, of $15 y^{\text {rs }}$. standing. There was a pat ${ }^{t}$. under treatment for varicocele ${ }^{21}$ of the cord. Other pat ${ }^{\text {ts }}$. much the same.

\section{/20v/ Sunday $7^{\text {th }}$.}

Went this morning to the Chapel $^{22}$ in the R. Bouloi. Did not like it quite so well as last Sunday. In the evening, was tempted to return, to hear a celebrated Independent preacher from London. ${ }^{23}$ Quite disappointed - not nearly so good a preacher as I expected - vastly prefer the usual Pastor. After all, nothing pleases me so much as the Ch. of England Service $-\&$ if Bishop Luscombe were not so poor a stick, \& the Church so far off, I $\mathrm{sh}^{\mathrm{d}}$. frequent it constantly. Next to the Ch. of England, I certainly prefer the Wesleyans, ${ }^{24}$ probably because they use our own beautiful \& eloquent Liturgy - \& because they support the opinion of the immense necessity of an established Church. ${ }^{25}$ Hence, in place of going to the Episcopal Cathedral, ${ }^{26}$ I frequent the Wesleyan Meeting, Rue Bouloi. Miserably tired, this Evening, \& by no means feel well. Something or other sadly disagrees with me, in my present manner of living - have scarcely been free from diarrhoea since I came to this house $-\&$ for the last two days, have been sadly plagued by Haemorrhoids. ${ }^{27}$

\section{Monday $8^{\text {th }}$.}

Went down to Hotel Dieu early this morning, but saw nothing worth going down for - thence went on to $S^{t}$. Louis. Several excellent cases there - particularly of Syphilis \& Herpes. Came back to Sichel's - a good case of central capsular cataract, ${ }^{28}$ \& Prolapsis of the Iris ${ }^{29}-\&$ several persons affected with sclerotitis, ${ }^{30}$ iritis, \&c.

Tuesday $9^{\text {th }}$.

Went down to Sanson's Ward at the Hotel Dieu this morning - absolutely nothing of any consequence doing there. Came back to La Pitié, with Andral - heard the Bruit de Soufflet

\footnotetext{
${ }^{21}$ Varicocele: dilatation of the veins of the spermatic cord resulting in a swelling.

${ }^{22}$ Chapel: places of worship attended by dissenters were often called chapels.

${ }^{23}$ Independent preacher: the early dissenters were the Presbyterians and the Congregationalists who were also known as Independents. (Evans, Modern state, p. 66.)

${ }^{24}$ This remark confirms that he was definitely not High Anglican.

${ }^{25}$ Methodism was regarded as a serious threat to the social order. In 1811 Viscount Sidmouth proposed a Bill introducing new restrictions on dissenting ministers. It was aimed principally at itinerants and was beaten off only after frantic lobbying by dissenters who emphasised, not for the first time, their unswerving loyalty to the established constitution. (Evans, Modern state, pp. 67-8.)

${ }^{26}$ Episcopal Cathedral: this could be the diarist's name for Luscombe's church.

${ }^{27}$ Haemorrhoids: a surprising condition in one so young.

${ }^{28}$ Central capsular cataract: in this condition the capsule surrounding the crystalline lens becomes opaque and increasingly disturbs vision. It is treated by either couching, or extracting the lens. (Hooper, Lexicon, p. 333.)

${ }^{29}$ Prolapsis of the iris: protrusion of the iris through a tear in the cornea.

${ }^{30}$ Sclerotitis: inflammation of the sclera of the eye.
} 


\section{9-10 December 1834}

very loud indeed, in a pat ${ }^{t}$. in the ward, in the carotid artery. Went to Lisfranc's ${ }^{31}$ Clinical Lecture - never saw a man make himself so perfect a buffoon, \& Merry Andrew. ${ }^{32}$ I was quite disgusted with him. It will be some time 'ere he sees me, there again - indeed / $21 \mathrm{r} / \mathrm{I}$ $\mathrm{sh}^{\mathrm{d}}$. not have gone today - but I knew he had an amputation. I was disappointed in his operating - his sawing, as with so many professional men, was miserable. The disease for which he amputated, was "white swelling" 33 of the knee. There are much fewer operations in Paris, than I had been led to imagine - indeed, hithertoo they had been really rare, tho' probably, from not attending Clin ${ }^{1}$. lectures, I have not seen many, which have occurred. Went to Sichell's, am delighted with this Dispensary. It is quite a new study to me, \& will assist in keeping me employed, now that I have nearly finished Dupuytren's Clinique ${ }^{34} \&$ Cazenave Sur les Maladies de la Peau. ${ }^{35}$ I have bought Welles [sic] in the French Translation, Sur les Maladies des Yeux. ${ }^{36}$ I wished to have obtained Lawrence ${ }^{37}$ or Mackenzie, ${ }^{38}$ but neither of them $\mathrm{c}^{\text {ld }}$. be had in Paris. I dare say J.B. Bailliére $[\mathrm{sic}]^{39} \mathrm{w}^{\text {ld }}$. have obtained them from London for me - but probably it will [be] more advantageous to read a French work - its price is a trifle only 8 francs. There was a rare case at Sichel's today, of dark brown effusion between the layers of the cornea produced, according to $S$. by effusion of albumen followed by effusion of blood, the liquid particles being absorbed, the colf[?] part ${ }^{\mathrm{s}}$. remained to tinge the albumen.

\section{Wednesday $10^{\text {th }}$.}

Went to the Hotel Dieu this morning with Sanson, afterwards with Chomel. I saw a case in his ward of well marked pleuro-peripneumony ${ }^{40}$ brought in last Evening - the

\footnotetext{
${ }^{31}$ Jacques Lisfranc (1790-1847), a provincial who had studied in Paris, had acquired surgical experience in the army before obtaining a hospital post. He was distinguished for his clinical lectures on surgical anatomy and for his surgical practice. In contrast to his earlier aggressive methods, Lisfranc later developed a more cautious approach to his surgery. (Ackerknecht, Paris Hospital, p. 146.)

${ }^{32}$ A Merry Andrew is defined as "one who entertains people by means of antics and buffoonery; a clown; properly (in early use) a mountebank's assistant". The American medical student Warren, who was studying in Paris at the same time as the diarist, described Lisfranc as a boisterous, "somewhat vulgar man". (Warren, Parisian Education, p. 92.) But whereas Warren described him as good natured to the students, the diarist obviously expected more formal behaviour.

${ }^{33}$ White swelling: hydrarthrosis, an oedematous (accumulation of fluid) condition of the leg due to thrombosis of the femoral vein.

${ }^{34}$ G. Dupuytren, Leçons orales de clinique chirurgicale, faites à l'Hôtel-Dieu de Paris, recueilliés et publiées par un Société de Médecins, 2 vols, Brussels, Ode et Wodon, 1832.

${ }^{35}$ The diarist may be referring to P. L. A. Cazenave and H. E. Schedel, Abrégé pratique des maladies de la peau, Paris, Béchet jeune, 1828, a second edition of which appeared in 1834. Pierre Louis Alphée Cazenave (1795-1877) continued the work of his mentor L. T. Biett at the St. Louis hospital on diseases of the skin.

${ }^{36}$ W. C. Wells, An essay upon single vision with two eyes, London, 1792. This was published later, in 1818 , with Wells's famous Essay on dew, as Two essays, London, 1818.

${ }^{37}$ William Lawrence, $A$ treatise on the diseases of the eye, London, 1833.

${ }^{38}$ William Mackenzie was at the time a specialist in Scotland on conditions of the eye. He lectured at the University of Glasgow and was one of the surgeons at the Glasgow Eye Infirmary. The diarist is probably referring to his A practical treatise on diseases of the eye, London, 1830, and also his Essay on diseases of the excreting parts of the lachrymal organs, London, 1819. His Treatise went through several editions.

${ }^{39} \mathrm{~J}$. B. Baillière was a well known French publisher and bookseller, whose books were sold in Oxford Street, London. Published catalogues of the firm's lists appeared regularly.

${ }^{40}$ Diarist's franglais for pleuro-peripneumonia (English) or pleuropéripneumonie (French).
} 
bowels had not been opened since Friday last - but nothing was ordered, as an aperient. Afterwards went into Breschet's wards. He kept me waiting more than a quarter of an hour. Saw a case of fracture of neck of scapula - crepitation ${ }^{41}$ was distinctly felt. Went to Sichell's, but it was such a miserable day, that there were very few patients there.

\section{/21v/ Thursday $11^{\text {th }}$.}

Went to La Pitié this morning with Louis, \& afterwards, heard part of Velpeau's Clin'. Lecture. Thursday is always nearly an idle day at the Hosp ${ }^{\text {ls }}$. At Hotel Dieu particularly, there is nothing going on. Went to Sichell's Dispensary. Saw some good cases of Iritis \&c. Heard a capital story of Roux at La Charité. He had a case under his care, for a tumor situated in the region of the sigmoid flexure of the colon. ${ }^{42}$ After the pat ${ }^{t}$. had been in for several days $\&$ he had well fingered \& examined it, he asked one morning, whether her bowels were open. The patient answered that she had not had a stool for 15 days. The Physician exclaimed with an oath, why the Divil did you not tell me of this before - as tho' it were not the duty of the Physician to make such necessary inquiries, particularly in a disease such as the one under treatment. The $D^{r}$. ordered a Lavement!! ${ }^{43}$

Friday $12^{\text {th }}$.

Went this morning to Hotel Dieu, with Sanson, \& afterwards attended his Clin ${ }^{1}$. Lecture. He told us today the reason why in the Parisian Hosp ${ }^{\text {ls }}$ in a case of fracture of the leg - this limb is raised nearly two feet from the bed by pillows $\&$ the thigh is on the inclined plane. The reason is, that when perfectly straight, pat ${ }^{\text {ts }}$. complain of pain $\&$ sore in the heel $\&$ when they are laid on their side with the knee bent, they are apt to turn round on their back \& have a crooked limb in consequence. The elevated position of the leg reunites all the advantages, without any of the disadvantages of both positions. Chomel was poorly \& did not lecture. Went round with Breschet - amongst his outpat ${ }^{\text {ts }}$. he had a case of small mellicerous encysted tumour ${ }^{44}$ under the scalp. He opened it thro' its whole extent, then laid hold of the cyst with $/ 22$ r/ a pair of forceps, $\&$ drew it out entire. Went to Sichell's - he had two excellent cases of cataract, \& of staphyloma of the Iris - \& another in which he had performed a famous cure of inflam ${ }^{n}$. of the choroid. Just ret ${ }^{d}$. from my Toucher - tired \& fatigued.

Saturday $13^{\text {th }}$.

Went down to Hotel Dieu this morning with Sanson. Attended his Clin ${ }^{1}$. Lect ${ }^{\mathrm{r}}$. on diseases of the eyes - he performed an operation for Ectropium ${ }^{45}$ produced by a cicatrix, underneath the

\footnotetext{
${ }^{41}$ Crepitation: elsewhere he uses the term "crepitus" to indicate the grinding sensation of the broken ends of fractured bones moving over each other, and the crackling noise heard, as a pathognomonic sound, when air is collected in cellular parts of the body.

${ }^{42} \mathrm{An} S$ shaped curve in the colon, the posterior part of the alimentary canal which leads into the rectum.

${ }^{43}$ Lavement: an enema.

${ }^{44}$ Misspelling of "melicerous", which refers to the thick, gelatinous substance found in certain tumours.

${ }^{45}$ Ectropium: eversion or turning back of a part, especially the eyelid.
} 


\section{3-15 December 1834}

eye. He cut out a V shaped piece of the lower lid, \& united it by the hairlip suture. Remained to ${ }^{46}$ Chomel's Clinical lecture \& was afterwards in time to go round with Breschet. By adopting this plan, one has great opportunities of seeing practice. Received a letter from Clifton today.

Sunday $14^{\text {th }}$.

Went to La Pitié this morning - nothing particular there. Heard cavernous respiration in one or two phthysical pat ${ }^{\text {ts }}$. \&c. Heard an excellent sermon from the preacher at the Chapel in the R. de Bouloi.

Monday $15^{\text {th }}$.

Went down to the Hotel Dieu this morning - Sanson applied a pomade of Chloride of Zinc ${ }^{47}$ to a cancerous sore. This was the only thing of consequence. Walked on to the $S^{t}$. Louis saw several cases of eczema - one uncommonly good - of a venereal eruption in the forehead putting on the characters of eczema - \& another very similar to Lichen Agrius. A beautiful \& most distinctly marked case of Herpes Zoster - two of Lepra - one of Psoriasis Syphillitica ${ }^{48}$ - of Erythema Papulatum ${ }^{49} \&$ a great many cases of that ever varying Protean disease, Itch. M. Cazenave declares, there is no such thing as "Pocky Itch" good a case of it today, combined also with Eczema Impetiginodes, as one $c^{\text {ld }}$. possibly desire. M. C. indeed acknowledges that pustules do occur, but he considers them pustules of Ecthyma. ${ }^{51}$ I saw in the wards today a tremendous case of $/ 22 \mathrm{v} /$ Eczema Impetiginodes, extending down the whole of the back of the legs - in a case of sciatica I saw the immense benefit arising from the application of a blister, dressed afterwards with Morphia. The man was, when I saw him last, in constant torture. He is today quite easy. There was a nice case of Herpes Preputialis ${ }^{52}$ in the wards, easily distinguished from Syphilis, yet I dare say it has by many men been frequently mistaken. I find, that I begin now to be able to recognise some of the more characteristic diseases of the skin. At first, when I commenced, everything was a desert. I tho'. I never $s^{d}{ }^{d}$ remember the names, much less apply them properly, but I quite despair of recognising the various forms of the Itch. Ret ${ }^{d}$. to Sichel's at $1 \frac{1 / 2}{2}$ - several good cases of diseases of the eye - but most of them old. By the bye, today at the $S^{t}$. Louis, a man

\footnotetext{
${ }^{46}$ Common error by those in daily contact with romance language speakers.

${ }^{47}$ Pomade of Chloride of Zinc: perfumed ointment.

${ }^{48}$ Psoriasis Syphillitica: Hooper distinguished psoriasis syphilitica from psoriasis guttata, which it resembles in the early stages but differs in some respects including the development of an ulcerated throat. Hooper found mercurial treatments of little benefit. (Lexicon, p. 1025.)

${ }^{49}$ Erythema papulatum: this condition involved a rash unaccompanied by fever which appeared chiefly on the arms, neck and breast in irregular patches of a bright red. This lasted about a fortnight, turned bluish and then declined. The constitution was affected, the patient feeling tired, pain in the limbs and loss of appetite, but soon recovered with a light diet and attention to the bowels. (Hooper, Lexicon, p. 556.)

50 "Pocky Itch": this refers to a pock - a pustule - seen in eruptive diseases especially smallpox.

${ }^{51}$ Ecthyma: a form of eczema often called impetigo, characterised by the eruption of large superficial pustules, developing into superficial ulcers covered with dark crusts and occurring chiefly on the lower limbs. See also November, note 197.

${ }^{52}$ Herpes preputialis [praeputialis]: Willan emphasised the importance of carefully diagnosing this condition. Because of their location, the herpetic clusters could be mistaken for chancres, with serious consequences for the patient. (Hooper, Lexicon, pp. 667-8.)
} 


\section{5-17 December 1834}

took out one of the small animalculae ${ }^{53}$ from the vesicles of an Itchy pat ${ }^{t}$. Lord Brougham ${ }^{54}$ was to visit the Hotel Dieu today.

Tuesday $16^{\text {th }}$.

Went to La Pitié, this morning, am always unfortunate, whenever I visit this Hosp ${ }^{1}$. Andral has no dissections and when I do not - he generally has. It is by far the best place in Paris for studying Pathological Anatomy. ${ }^{55}$ At Sichel's, we had some good cases - one, in which the lymph producing adhesions between the Iris, \& the capsule of the crystalline ${ }^{56} \mathrm{c}^{\text {ld }}$. be distinguished by means of the magnifying glass - another, in which there was union between Iris \& capsule of crystalline \& discoloration of latter by the uvea. ${ }^{57}$ In another case, there was a dirty brown effusion between the layers of the cornea, covering a portion of the pupil. The difference of color between the "Tache", 58 \& the pupil was so trifling, that without great care, \& without a certain light it $\mathrm{w}^{\text {ld }}$. not be discovered, \& a practitioner $\mathrm{w}^{\text {ld }}$. be apt to say, that there was nothing the matter with the eye.

/23r/ Wednesday $17^{\text {th }}$.

Went to La Pitié this morning - no autopsy. Am paying some attention to the stethoscope again - find I have forgotten the majority of the sounds, I knew, when in Edin ${ }^{\mathrm{b}} .^{59}$ I fear the use of this inst ${ }^{t}$. will never be so extensively diffused as its immense importance requires, for this reason, that persons not in the constant, almost daily habits of employing it, will forget all but the most characteristic \& well marked sounds. These, when a person has once heard, will ever remain afterwards firmly fixed in his mind - but I defy a man with moderate opportunities of observation, to distinguish between a loud mucous râle \& a "gargouillement". 60 The differences may be laid down in books, but in many cases, they approach each other so closely, that it is almost impossible to say where one ends \& the other begins. These observat ${ }^{\text {ns }}$. are prompted by the consideration of a case in Andral's ward, in which "gargouillement" is present in the upper part, \& a loud mucous râle almost precisely similar is heard throughout the right lung - in the upper part of the left, there is a loud puerile

\footnotetext{
${ }^{53}$ According to Hooper, some writers ascribed the origin of the itch in all cases to the presence of minute insects burrowing in the skin while others doubted the existence of such insects. But Hooper claimed that, in some cases of scabies, insects had been the cause, and this had been demonstrated. (Lexicon, p. 1095.)

${ }^{54}$ Henry Brougham (Baron Brougham and Vaux) (1778-1868) was a Whig politician, reformer and economist who devoted considerable time to education and law reform. (Evans, Modern state, pp. 51, 108, 224-5.) He was associated with the founding of the Society for the Diffusion of Useful Knowledge, and the University of London with its Faculty of Medicine. He had been Lord Chancellor under the Whig government of Earl Grey (November 1830 to July 1834) and continued in office under Viscount Melbourne (July to November 1834). He was clearly interested in visiting Paris to examine its social institutions, such as the renowned Hôtel Dieu, at a time of political unrest in England - to which the diarist has referred - and which had led to the caretaker administration of Wellington. This government lasted only two months.

${ }^{55}$ Pathological anatomy: Ackerknecht describes the period 1794-1848, as one of "pathological anatomy", succeeded by the new medicine of "laboratory medicine" under the leadership of Louis Pasteur and Claude Bernard. (Paris hospital, p. xiii.) Pasteur and Bernard were able to pursue their new experimental investigations relevant to medicine and make significant progress by calling on the rapidly developing sciences.

${ }^{56}$ Crystalline: the lens of the eye.

${ }^{57}$ Uvea: pigmented part of eye, including the iris, ciliary body and choroid.

58 "Tache": speck or stain on the cornea.

${ }^{59}$ This indicates that stethoscopy was part of the medical curriculum in Edinburgh.

60 "Gargouillement": a gurgling or rumbling sound as in a rumbling stomach or, as in this case, discernible in the lungs.
} 


\section{7-18 December 1834}

respiration, ${ }^{61}$ which in one spot was tho ${ }^{t}$, by some to be cavernous. The dissection in this case will be very interesting. I heard today, of a case, in the H. Enfans Malades, ${ }^{62}$ in which the "Bigwigs" were completely out. A little child was considered, labouring under the third stage of pneumonia ${ }^{63}$ in both lungs. A friend of mine one day, when there, told the Interne he certainly heard gargouillement - but the latter said, $c^{\text {ld }}$. be no such thing. On examination - in this spot there was found an immense cavity, three or four smaller excavations throughout the two lungs, $\&$ an immense development of tubercles. ${ }^{64}$ Surely such a mistake, as this, must have arisen from pure negligence on the part of the medical attendants. I did not go to the $S^{t}$. Louis this morning, \& consequently, they had some admirable cases - one of congenital Icthyosis, ${ }^{65} / 23 \mathrm{v} /$ with Impetigo Figurata ${ }^{66}$ on the face. Another of Barbadoes $\operatorname{leg}^{67}$ in a man, who had never been in warm climates. Several syphilitic sores, \& one or two of Noli me Tangere. ${ }^{68}$ Went to Sichel's - a miserable day, \& consequently few patients there.

Thursday $18^{\text {th }}$.

Went to Andral's Ward at La Pitié - nothing new - went to Velpeau's lecture - he is on diseases of the eye every Thursday. ${ }^{69}$ Did not like his matter much, so I left in the middle \& walked off to my Salon Litteraire. This I believe is the end of my month there - don't think I shall subscribe again. Was at Sichel's - nothing particular. Thursday is the most idle day in the week.

\footnotetext{
${ }^{61}$ Puerile respiration: loud pulmonary murmur in children, but in adults this usually indicates disease.

${ }^{62} \mathrm{H}$. Enfans Malades: the full name of this hospital for sick children at number 7, rue Sèvres, was Hôpital des Enfans Malades.

${ }^{63}$ Pneumonia: also pneumonitis, peripneumonia; inflammation of the lungs characterised by fever, difficulty in breathing, cough and a sense of weight and pain in the thorax. It was thought to be mostly produced by exposure to the cold. At the onset, the pulse is usually full, strong, hard and frequent but becomes weak, soft and irregular. Initially, the cough is frequent, dry and without expectoration but later becomes moist and the expectorate may be tinged with blood. If the inflammation cannot be checked in time the outcome could be fatal. Bleeding was freely recommended, the bowels were kept open and antimonials and mercurials, the large group of pharmacological substances containing mercury, used in the treatment of a range of diseases, were administered. (Hooper, Lexicon, pp. 988-9.)

${ }^{64}$ Presumably the diarist is describing the results of an autopsy.

${ }^{65}$ Icthyosis: misspelling for ichthyosis, a congenital disease of the skin, characterised by dryness and scaliness. It was called the fish skin disease because of the resemblance of the thickened, hard, rough skin to fish scales. This unsightly condition, which could begin early in life, appeared in patches which might cover most of the body. The disease showed little response to medicines, including ointments and plasters. Picking off the scales with the nails was sometimes resorted to but the skin below never returned to its former condition although warm baths with moderate friction kept the scales away. A form of the disease with really horny-like excrescences was rare. (Hooper, Lexicon, pp. 708-9.)

${ }^{66}$ Impetigo Figurata: sometimes confounded with herpes circinatus, this is the most common variety of moist impetigo. It occurs in circumscribed patches of closely set yellow pustules with slightly inflamed edges and of various shapes and sizes. After some days, the pustules begin to dry and form scabs which fall off in two to three weeks leaving the skin red and rough. The sense of burning and intense itching at the beginning was little eased by any of the applications tried. (Hooper, Lexicon, pp. 715-16.)

${ }^{67}$ Barbadoes leg: this disease was indigenous, but not confined, to Barbados and, in fact, occurred widely in the region. The affected limb became tumid, hard, livid and very misshapen, with the skin thick, scaly and warty. The condition was thought to involve inflammation of the lymphatics of the limb and, as it progressed, it brought on febrile paroxysms and a very poor outlook for the patient. (Hooper, Lexicon, pp. 228-9.)

${ }^{68}$ See November, note 55.

${ }^{69}$ Whilst Sichel came to be seen as the main ophthalmologist in Paris, at this stage Velpeau and others also dealt with diseases of the eye.
} 
Friday $19^{\text {th }}$.

Went to Sanson's this morning at the Hotel Dieu. Saw nothing there of any importance returned to La Pitié. Andral was not there - followed Louis. Am quite surprized [sic] at the number of pat ${ }^{\text {ts }}$. with tubercles in the lungs in these wards - if indeed Louis is to be believed $\&$ his diagnosis to be trusted. More than half the pat ${ }^{\text {ts }}$. have according to him tubercles. This is the diagnosis always, when there is any dullness under the clavicles. Frequently I have no doubt he is mistaken. ${ }^{70} \mathrm{I}$ like Chomel better as a practitioner, than any other that I have yet seen. Went to Sichel's. Several capital cases of staphyloma - treated by application of Nitrate of Silver. He is very fond of using an unguent of Mcy: Hyd: ${ }^{71}$ \& Ext: Belladon: ${ }^{72} \mathrm{He}$ is successful in his treatment generally, but a most miserable operator. He says that the difference in appearance between inflam ${ }^{n}$. of the memb ${ }^{e}$. of the aqueous humour $\&$ of the substance of the Iris itself, was that in the former the striae[?], ${ }^{73}$ tho' altered in appearance $\mathrm{c}^{\text {ld }}$. be distinguished, in the latter they $\mathrm{c}^{\text {ld }}$. not. Have been reading L. Bulwer's ${ }^{74}$ Pamphlet on the present crisis addressed to one of the late Cabinet Ministers, Lord Duncannon $?^{75}$ It is powerfully $\&$ forcibly written. It will do his cause service $-\&$ what is of more consequence to him, it will ensure his reelection. There can be no doubt, that /24r/ Parliament will be dissolved - but I question much, whether a sufficiently powerful Tory party will be returned to give the Ministry hope of retaining the reins of Government. ${ }^{76}$ God grant we be not cursed by a Durham administration. ${ }^{77}$ If the Tories be defeated, it will be entirely owing to the refusal of Stanley ${ }^{78}$ to join them. I care nothing \& say nothing on Politics, but I am surprized that Peel's ${ }^{79}$ prudence sh $^{\mathrm{d}}$. so far

\footnotetext{
${ }^{70}$ Louis was seen by many as having an obsession about the presence of tubercles in the lungs. See January 25, note 165 .

${ }^{71}$ Unguent: any soft substance used as an ointment or for lubrication. Hyd: the contraction for hydrargyrum, a mercury-containing compound, in this case one similar to the "blue" ointment which was still used in the Second World War as a delousing agent.

${ }^{72}$ Extracts of belladonna were used as powerful sedatives and narcotics, also as diuretics, and, according to Milne-Edwards and Vavasseur, were useful for action on the iris, to obtain enlargement of the pupil and before operations for cataract (Nouveau formulaire, p. 333). Dupuytren, like Sichel, also used belladonna in the treatment of eye conditions.

${ }^{73}$ Striae: streaks or lines in the iris, as in this case, or in the teeth, see December 30.

${ }^{74}$ This is probably Edward George Earle Lytton Bulwer-Lytton, Ist Baron Lytton (1803-73), MP for St Ives from 1831-41. (See also November 3, note 53)

75 John Ponsonby, Viscount Duncannon (1781-1847), a Whig Peer, had served as Home Secretary in Lord Melbourne's first administration of July to November 1834, which had followed the resignation of the Whig Earl Grey in July 1834. Duncannon returned as Lord Privy Seal in Melbourne's second government of April 1835 following the fall of Sir Robert Peel's Conservative administration on the Irish Church issue. (Evans, Modern state, pp. 470-1.)

${ }^{76}$ The diarist was correct in predicting that a Tory administration was probably not powerful enough to retain the reins of power.

${ }^{77}$ John George Lambton, 1st Earl of Durham (1792-1840), had been Lord Privy Seal in Earl Grey's Whig administration of November 1830 to November 1833. As part of the drive for social reform and to avert public unrest some three years earlier, Durham had argued unsuccessfully for the creation of new peers. (Evans, Modern state, p. 264.)

${ }^{78}$ Edward Stanley (1799-1869) had been the Chief Secretary for Ireland in Earl Grey's administration but had resigned in 1833 before it fell in 1834 . On his father's death, he became 14th Earl of Derby.

${ }^{79}$ Sir Robert Peel (1788-1850), a Tory who opposed Catholic emancipation and reform of the House of Commons, but who realised, nevertheless, that some social reform was needed. He also came to accept that civil strife was a greater danger than the emancipation of Catholics.
} 


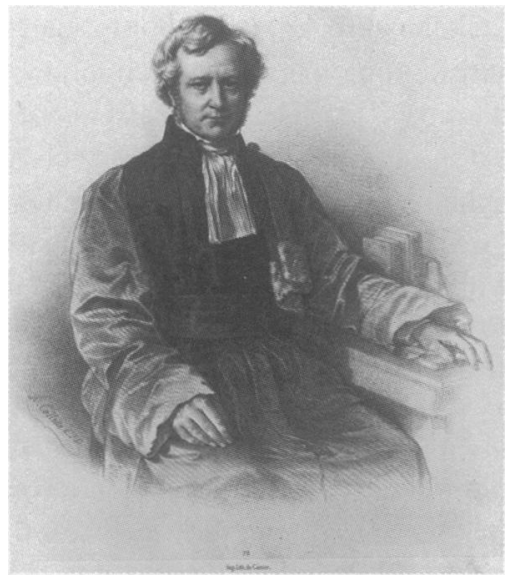

Figure 8: Auguste François Chomel (17881858). Lithograph by A. Collette. (Wellcome Library, London.)

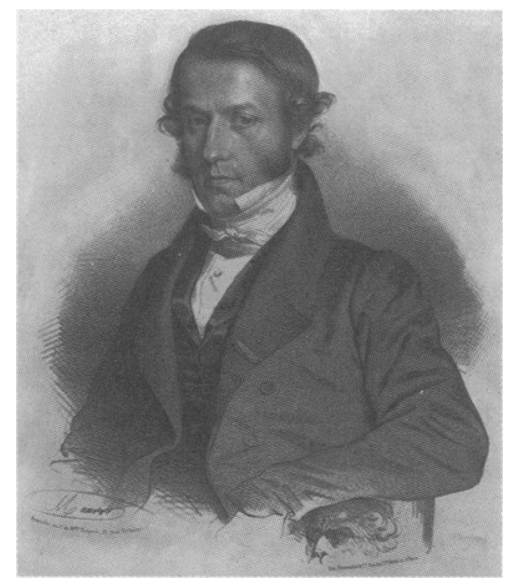

Figure 9: Gabriel Andral (1797-1876). Lithograph by N. E. Maurin. (Wellcome Library, London.)

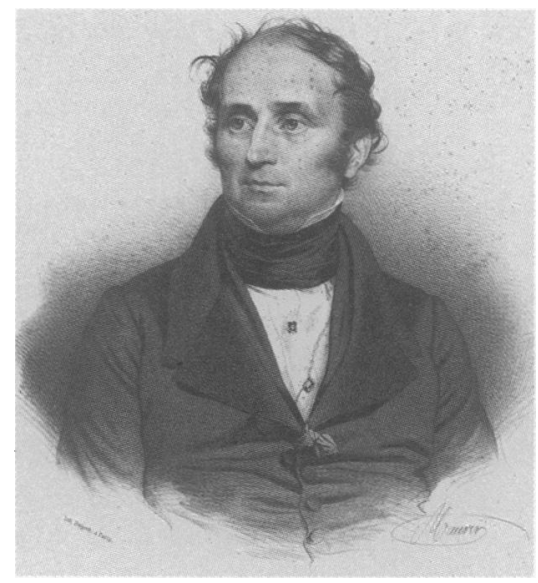

Figure 10: Louis Joseph Sanson (1790-1841). Lithograph by

N. E. Maurin. (Wellcome Library, London.)

have deserted him, as to allow anything to induce him to endeavour to form a high Tory Government. $^{80}$

Sat ${ }^{y} .20^{\text {th }}$.

Went down this morning to Hotel Dieu - had an excellent lecture from Chomel. I like him better than any Physician I have seen in Paris. Have been in my present lodgings a month

${ }^{80}$ Peel was elected member for Tamworth in August 1833. He was described as the most liberal of Conservatives and the most capable man of all in both parties. During 1833-34, he sided with the Whig government no fewer than eighteen times. Hence the diarist's surprise that he should have even contemplated trying to form a high Tory government. 
today - paid Madame. Still continue as before not to take my breakf ${ }^{t}$. in the house. Entered this morning for another month to my Salon Litteraire. ${ }^{81}$

Sunday $21^{\text {st }}$.

Went to Andral's wards at La Pitié this morning - capital P.M. ${ }^{82}$ Examination - one which proved most incontestibly what I had suspected ever since I have been in Paris, viz. that the Physicians mark down many cases as Phthysis, which are not indeed produced by tubercular excavations in the lungs. In this woman, the diagnosis was tubercular infiltration of the whole of the left lung, \& a large cavity on a level with the left breast. On examination not a single tubercle in either lung \& no cavity - but the whole of the left lung in a state of Hepatization $^{83}$-..-- Having mentioned this case more at length in my notebook I shall not further allude to it here. Wrote to Clifton today, \& sent it by Ainslie ${ }^{84}$ to be put into the London Office. Also sent by the same hand, a letter to Syme at $\mathrm{Ed}^{\mathrm{n}}$. to inquire the latest time at which I may have an examinat ${ }^{\mathrm{n}}{ }^{85}$

Monday $22^{\text {nd }}$.

Went to Hotel Dieu, \& thence to the H. St. Louis - nothing particular there this morning several cases of Itch but nothing else. In the wards, tho' is a case of superficial Lupus of the hand \& elbow - very rare. Went to Sichel's $-/ 24 v /$ several interesting cases, but S. not there - great annoyance.

Tuesday $23^{\text {rd }}$.

Ainslie left last Evening - wish I $c^{\text {ld }}$. leave this horrid place. I firmly believe Paris is the most miserable hole that any poor mortal was doomed to exist in during the winter - it is even worse than Bristol - \& that I think, anyone will admit, is bad enough. To an idle man, living in the neighbourhood of the R. de la Paix, Paris may be pleasant, but to a medical student dragging out his life in the Quartier du Jardin du Roi, it is miserable. Went this morning to Andral's ward \& then to Breschet's at the Hotel Dieu, nothing very particular in either. Was at Sichel's - saw an old case of Staphyloma Iridis, covered by false memb ${ }^{\mathrm{e}}$. - subsequent to

\footnotetext{
${ }^{81}$ Frenchified English.

${ }^{82}$ P. M.: post mortem, not to be confused with post meridian (after midday) for which he uses the same capitalised acronym.

${ }^{83}$ Hepatization: the change of lung tissue into a condition in which it resembles the liver in consistency, as in lobular pneumonia.

${ }^{84}$ The diarist himself was unsure of the spelling of this name, which has been partly corrected. It could be William Ainley who gained an LSA in 1835 and an MRCS in 1836. He could also have been studying at Edinburgh - to qualify as a surgeon - because he seems to be in a position to take the diarist's letter back to James Syme in Edinburgh. (London and Provincial Medical Directory, 1849, p. 252.)

${ }^{85}$ The diarist would seem to be writing to Syme to check the administrative details - the Rules and Regulations - of his final examination in Edinburgh. James Syme (1799-1870) was professor of clinical surgery at Edinburgh and an expert in a number of surgical procedures, for some of which he had devised special instruments. His procedures included attending to fistulae, stricture of the urethra and amputation at the ankle instead of higher up. On the death of Robert Liston in 1847, Syme accepted an invitation to succeed him as professor of clinical surgery at University College London. Syme went to London in February 1848, but, owing to a misunderstanding with regard to the conditions of the appointment, he resigned in May and in July returned to his unfilled chair in Edinburgh. He was elected president of the Medico-Chirurgical Society of Edinburgh. (DNB, vol. 19, pp. 266-7.)
} 


\section{3-24 December 1834}

purulent Ophthalmy. ${ }^{86}$ An excellent case also of Scrophulous Conjunctivitis, ulcer of the cornea, large \& superficial - Keratitis, ${ }^{87}$ effusion between the layers of the cornea sclerotitis, Iritis. His treatment was very judicious $-\mathrm{VS}^{88}$ - purging every other morning with Eau de Seidelitz ${ }^{89}$ - Calomel \& Sulph. Antim: ${ }^{90}$ aa gr. $1 / 4$ ter die $^{91}$ - Leeches to the temples cras $^{92} \&$ applic: of Belladonna. ${ }^{93}$ Also an excellent case of deep Lenticular ${ }^{94}$ Cataract.

Wednesday $24^{\text {th }}$.

Went to the Hotel Dieu - Sanson there very late so went into Chomel's ward. Several fever pat $^{\text {ts }}$. Went off to the H. S ${ }^{t}$. Louis - followed Biett - afterwards went into Alibert's lecture. Saw him apply strong fuming Muriatic Acid, to the arm of a person with Eczema - it produced an immediate eruption of vesicles - to another case of same diseases on the finger, he applied Nit: of Silver. ${ }^{95}$ I shall be able to see which is the best - both act $/ 25 \mathrm{r} /$ in the same way, by altering the action of the surface, to which they are applied - the former produced some consid ${ }^{1}$ - pain \& the latter has the inconvenience of rendering the part black. Saw a case of scrophulous sore (superficial) of the cheek - he had applied Pommade of Protoiodide of Mercury ${ }^{96}$ with the best effects. After the visit, I went round the premises with Mr. Strauss[?], the Externe ${ }^{97}$ of Baron Alibert. Saw the place, where fumigations ${ }^{98}$ of all kinds are administered - the apparatus consists of a wooden box with a kind of chair for the pat ${ }^{\mathrm{t}}$. to sit in - the cover has a hole through which

\footnotetext{
${ }^{86}$ Purulent Ophthalmy: this should be purulent ophthalmia. The condition was listed in Larousse médical as ophthalmie purulente and was common in gonorrhoeal conditions or with conjunctivitis of the newborn.

${ }^{87}$ Keratitis: inflammation of the cornea.

${ }^{88}$ VS: venesection, i.e. bloodletting.

${ }^{89}$ Seidelitz: misspelling of Seidlitz. See this month, note 3.

${ }^{90}$ Sulph. Antim: sulphuretum antimonii was used in large doses to promote vomiting and purging.

${ }^{91}$ The letters " aa" indicated "of each ingredient" named in the prescription, followed in this prescription by the quantity, viz. "gr'//4", one quarter of a grain to be included in the preparation. Ter die, indicates that the dose should to be taken three times a day.

${ }^{92}$ Cras: this is a Latin term for "tomorrow" or "next day", and here indicates that the leeches were to be applied on the following morning.

${ }_{93}$ Belladonna was used in this case to cause mydriasis or extreme dilatation of the pupil.

${ }_{95}$ A condition pertaining to the crystalline lens of the eye.

${ }^{95} \mathrm{Nit}$ : of Silver: silver nitrate, one of the nitrates used as a caustic substance to burn away the diseased tissue. (Hooper, Lexicon, pp. 1880-1.)

${ }^{96}$ Protoiodide of mercury was a highly poisonous substance but in very small doses was considered useful in the treatment of scrofulous conditions complicated by syphilis. (Milne-Edwards and Vavasseur, Nouveau formulaire, p. 256.)

${ }^{97}$ Externe: the leading surgeons and physicians in the main Paris hospitals had a number of externes. These were successful medical students who obtained promotion to junior non-residential clerks, having gained their one or two year positions through the system of competitive examinations or concours. These externes aspired to join the smaller group of the even more prestigious cadre of internes who held four-year hospital "internships" gained through a further system of concours. They received room and board plus a small stipend and each interne went through an intense apprenticeship under the direction of their surgeon or physician "boss". See also January 4, note 26. (Weisz, Medical mandarins, pp. 239-40.)

${ }^{98}$ Fumigations: treatment of skin diseases with what were held to be fumes of therapeutic substances such as those containing sulphur or mercury, as noted by the diarist. Fumigation could also be local, for a single limb or for the ear or nose. (Larousse médical, p. 468.)
} 


\section{4-25 December 1834}

the head projects - the bottom is of iron, which is warmed by means of a stove placed underneath. On the bottom, the herbs, for aromatic, sulphur for sulphurous, the Sulpht. of Mercury for mercur ${ }^{1}$. fumigat ${ }^{\text {ns }}$., is placed. The pat ${ }^{\mathrm{t}}$. sits on the chair, his head projects thro' the hole \& a blanket is wrapped round the neck to prevent the fumes surrounding the face \& head. When alcohol is employed, it is poured thro' a long pipe, reaching from the cover to the bottom. After coming out of this bath, the patients are wrapped entirely in blankets \& remain for some considerable time, in the bathing room, at an elevated temperature, so as to perspire freely. The warm \& cold baths are arranged in rows with two pipes to each -36 in a room - these bathing tubs are used, not only for simple, but for medicated baths of all descriptions - thus gelatinous are formed by adding a solut ${ }^{\mathrm{n}}$ of glue (about 2lbs) to the simple - Alkaline by adding Potass or Soda \&c. \& so also with acid baths. ${ }^{99}$ In another part of the premises, we found a large digester, in which they made the soup for the supply of the Hospital - from the gelatine of bones. It is necessary for this purpose, to have a higher temp ${ }^{\mathrm{e}}$. than that of boiling water under the usual pressure - hence Papin's Digester ${ }^{100}$ is used. $/ 25 \mathrm{v} /$ In another part of the premises, we saw some outhouses, in which $\mathrm{Gas}^{101}$ for the lighting of the Hospital was made, together with four large Gasometers. Altogether it is quite a village within itself - covering a very large space of ground - \& containing a considerable number of inhabitants, 1200 pat $^{\text {ts }}$., I think. Went to Sichel's saw some capital cases, principally of Staphyloma. A very favourite ointment of his, is Ung: Hyd: Ext: Bellad: being: fract: aequal: bis die utend circ: oculos. ${ }^{102}$

Thursday $25^{\text {th }}$.

This is Xmas day - how differently I sh ${ }^{\mathrm{d}}$. spend this day in England with my own family circle. Went to Andral's Ward - thence to Breschet's. B: did not come - started at 101/2 to hear high mass in $S^{t}$. Roch ${ }^{103}$ delighted beyond measure - the music was beautiful, truly sublime - but the effect was much lessened at least in my opinion, by the horrid mockery of the service - five or six priests walking one after the other, holding aloft the cross - dressed in yellow silk \& gold preceded by two servants, splendidly attired, wearing gold epaulets \& swords \& carrying each a large staff. Several boys followed with candles \& small white surplices, \& the whole procession concluded by the march of several minor priests. How is it possible, that any persons of common sense can belong to such a church as this? The edifice

\footnotetext{
${ }^{99}$ Therapy of baths: Hooper deals with the medical value of therapeutic waters such as those of Bath and other spas. (Lexicon, pp. 232-4.)

${ }^{100}$ Papin's digester was a strong airtight iron kettle or copper, furnished with a safety valve, in which bodies could be subjected to the vapour of water, alcohol or ether at a pressure above that of the atmosphere. (Hooper, Lexicon, p. 485.)

${ }^{101}$ This comment about the Hôpital St. Louis having its own system of gas supply indicates the advanced nature of many of the facilities in this large, leading Paris hospital.

${ }^{102}$ The prescription indicated that the ointment (Ung: unguentum), which contained mercury (Hyd: hydrargyrum) and extract of belladonna (Ext: Bellad:), was to be spread around both eyes twice daily.

${ }^{103}$ St. Roch parish church, in the rue St. Honore in the second arrondissement, had its foundation stone laid by Louis XIV but was not built until 1750. It was unusual in that it extended from north to south (due to lack of space) instead of from east to west. It had a magnificent flight of steps leading to the portal and its pulpit, supported by colossal sculptures of the four evangelists at its base, was greatly admired, as was the picture of the crucifixion facing the pulpit. Not surprisingly, midnight Mass on Christmas Eve was among its special occasions. (Galignani's new Paris guide, pp. 80-4.)
} 


\section{5-26 December 1834}

of $S^{t}$. Roch is magnificent, \& several of the altars superb. The whole of the interior was crowded, \& an immense number /26r/ of persons, similar to myself, walking about to see what was to be seen - it was quite impossible, for the really sincere worshippers, to come to the House of God, with what the Protestants consider, a proper spirit. They appeared to say their prayers mechanically, looking around them at the multitude \& at the procession, $\&$ every few minutes they were obliged to get up to move their chairs to allow some functionary or other to pass $-\&$ then in the midst of it all, it was so amusing to see a person come round to collect the sous for the use of the chairs. None of these disturbances seem to interrupt the saying of their prayers - they appeared to be in a very enviable state of indifference. After coming away from such a display as this, one ceases to wonder at there being so little religion in France - the extraordinary thing is, that the R. Catholic Church $s^{d}$ find a single supporter in the $19^{\text {th }}$. century. From $S^{t}$. Roch, I went to the R. de Bouloi - here everything was conducted as I think it ought to be. All the persons appeared imbued with proper feelings $\&$ proper ideas - there was no fuss, no ceremony $-\&$ no disturbance. It was quite impossible not to feel the immense superiority of the Protestant over the R. Catholic form of worship. In the Evening there was a kind of family party assembled at this Pension. I $c^{\text {ld }}$. not help contrasting the difference between it $\&$ our usual Xmas parties in England. This beastly Paris, I detest it more \& more every day of my life.

\section{Friday $26^{\text {th }}$.}

Went to the Hotel Dieu. Heard a capital lecture from Chomel - has proposed himself decidedly a believer in the fact that the antivariolous power of vaccination becomes diminished by time. ${ }^{104}$ This appears to me, from all the arguments, which /26v/ I have seen \& heard on the subject, to be the only rational opinion which we can arrive at, $\&$ hence I think it is right that every person $\mathrm{sh}^{\mathrm{d}}$. be revaccinated after a certain length of time. ${ }^{105}$ As Chomel said, if it does not rise, no harm is done - if it does \& goes through its regular stages - it is certain that the system was not before fortified against variola. ${ }^{106}$ Breschet came early this morning, viz at 9 oclock, whilst I was with Chomel. I therefore lost the opportunity of going round with him - he seldom visits his wards before 10 . Went to Sichel's - saw some very

\footnotetext{
${ }^{104}$ The diarist is here referring to the practice of vaccination against variola or smallpox based on the work of Edward Jenner (1749-1823) who is associated with the finding that inoculation with the cowpox "virus" confers protection against the more serious and common, highly contagious condition of smallpox. Universal adoption of the practice of vaccination depended on developing a method which ensured that the recipient did develop the protective cowpox. Cowpox and smallpox could co-exist in the same individual. (Hooper, Lexicon, pp. 439-43.)

${ }^{105}$ Hooper acknowledged that a "much controverted" issue at the time, concerning "vaccine inoculation", was the permanency of its effect against smallpox. Hooper was of the opinion that "it is nothing less than a perfect and permanent security against that terrible disease". (Lexicon, p. 440.)

${ }^{106}$ Variola: smallpox, a very contagious disease that disfigures the skin with its eruption of red pimples followed by their drying up and falling off in crusts, leaving the skin pitted in many cases. It attacked individuals of any age but the young of both sexes were more vulnerable. It was held to be produced either by breathing air impregnated with the effluvia arising from the bodies of those infected, or by contact with the suppuration from the pimples or the clothes of an infected person. The condition went through four stages: febrile, eruptive, maturative and scabbing. It varied in severity and could prove fatal between the eighth and the eleventh day. Treatment varied according to the nature of each case, tepid baths and cooling of the eyes if affected, plus the administration of doses of Peruvian bark or cinchona. (Hooper, Lexicon, pp. 1258-60.)
} 


\section{6-27 December 1834}

good cases of Staphyloma - corneitis ${ }^{107} \& \mathrm{c}$. Afterwards to Andral's lecture for the first time for weeks - it is most tiresome to me now to attend lectures $\&$ the professors are too fond of "splitting hairs" to use a common English expression. Since I have been attending at Sichel's, I have seen two persons with a glass eye each - they were so well made, \& so exactly like the other, that it is with considerable difficulty, the deception can be discovered. ${ }^{108} \mathrm{I} \mathrm{w}^{\text {ld }}$. much prefer one of them to the squinting eyes one sometimes sees. The artificial eye is moved slightly by the motion of the remains of the ball[?] forming its cushion \& support - this together with the action of the eyelids, prevents the deformity from being very manifest. In each case, many of the students were puzzled to discover why the pat $^{\mathrm{t}}$. came to the dispensary.

\section{Saturday $27^{\text {th }}$.}

Went to Chomel's. Saw Sanson endeavour to reduce a dislocation of the shoulder of two months' standing. It appears, there had been a fracture of the humerus, which prevented the dislocation from being reduced, when it occurred $/ 27 \mathrm{r} /$ he had no pullies - merely assistants $-\&$ had not used any means of depletion. ${ }^{109}$ After continuing extension for about $11 / 2$ minutes he gave up, sent the man back into the ward, $\&$ ordered him a warm bath $\&$ to be bled. It was perfect folly to attempt the reduction without these preliminary measures being had recourse to. Chomel gave us a capital Clinical Lecture on a case of Typhus fever terminating fatally with peritonitis ${ }^{110}$ by escape of faecal matter thro' a perforating ulcer in the intestine. Ulcers were very numerous in both the small \& large intestine - more especially in the former. Went to Sichel's lecture - he was on wounds of the globe of the eye \& Traumatic Ophthalmia. Was in Breschet's wards this morning - saw several very interesting cases. Amongst them, was one of Phlegmasia Dolens ${ }^{111}$ or Crural Phlebitis ${ }^{112}$ in a very fine girl of 18 , following suppression of the menses. Saw M.B. remove an encysted tumor, from the side of the face - he ran a straight Bistouri ${ }^{113}$ thro' the cyst evacuated the caseous ${ }^{114}$ matter contained in it, then laid hold of the membrane with a pair of forceps, \& extracted it with considerable ease. At the Consultation Gratuite, a man applied, with partial dislocation of the knee.

${ }^{107}$ Corneitis: inflammation of the cornea.

${ }^{108}$ Larousse médical agreed with the diarist concerning the quality of the artificial eyes available. Artificial eyes were made in enamel and so perfectly resembled healthy eyes that it was difficult to tell them apart ("Les yeux artificiels sont fabriqués en émail, d' une façon si parfaitement semblable à des yeux sains qu' il est difficile de s'apercevoir de la substitution" [p. 802]). Guidance was provided on their maintenance.

${ }^{109}$ Depletion: bloodletting, probably with leeches.

${ }^{110}$ Peritonitis: inflammation of the peritoneum, the membrane covering the organs and lining the cavity of the abdomen. The symptoms of peritonitis include fever, pain and tenderness in the regions affected. Treatments included bleeding with leeches, blisters, warm baths and fomentations. (Hooper, Lexicon, p. 951.)

${ }^{111}$ Phlegmasia Dolens: inflammation. Phlegmasia alba dolens was referred to as "white leg", a painful swelling of the leg sometimes, unlike this case, caused by septic infection following childbirth. (Hooper, Lexicon, p. 961.)

${ }^{112}$ Crural Phlebitis: inflammation of the walls of a vein and in this case the reference to "crural" indicates that the leg was the location of the condition.

${ }^{113}$ Bistouri: the French spelling for a long slender curved or straight surgical knife or bistoury, in English. (Hooper, Lexicon, p. 247.)

${ }^{114}$ Caseous: substance of soft cheese-like consistency. 


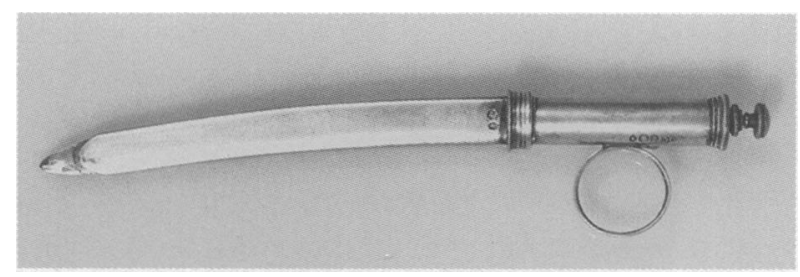

Figure 11: A concealed bistoury, 1836. (Photo, Wellcome Library, London.)

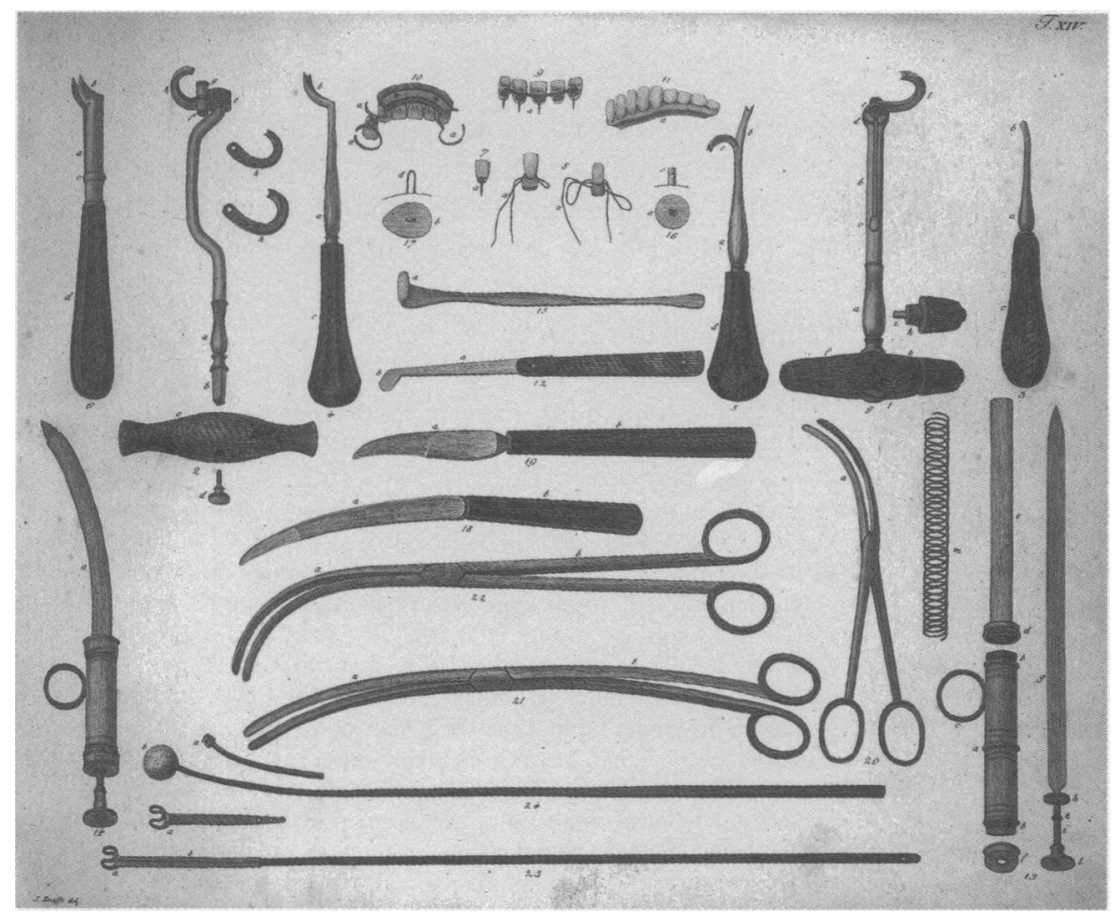

Figure 12: Dental instruments. Engraving c. 1820 by Krafft after K. Ponheimer, from Franz Xaver von Rudtorffer, Armentarium chirurgicum selectum, Vienna, 1817-1820, Plate 13. (Wellcome Library, London.)

Sunday $28^{\text {th }}$.

Went to Andral's. A. not there - so went into Louis' ward. Nothing particular there - but as usual L: said almost every pat ${ }^{\mathrm{t}}$. had tubercles in the lungs. Went to the R. de Bouloi - had an excellent sermon on self examination. Mr. Newstead is certainly an extremely good \& energetic preacher, I like him very much ${ }^{115}$ - went again in the Evening - the shops \& streets

${ }^{115} \mathrm{Mr}$ Newstead was the preacher at the chapel/church in the rue du Bouloi which the diarist most frequently attended on Sundays. 


\section{8-30 December 1834}

are exceedingly gay today, \& have been all the last week, with toys, Bonbons, clothes, \&c $\& c$ this being the season of the year at which persons make presents to all their acquaintance.

Monday $29^{\text {th }}$.

Went to Chomel's, \& thence to the H. S ${ }^{t}$. Louis - we had some excellent cases of Impetigo, of Eczema Impetiginodes, of Lupus, of Pityriasis \& of Psoriasis. At Sichel's, we had some good examples of Adherent Iris, ${ }^{116} \&$ of Strumous Ophthalmia. ${ }^{117}$ Afterwards walked down to the Institute, ${ }^{118}$ but there was no public meeting today, as the Eloge on Cuvier ${ }^{119}$ was to be read - this indeed was what we wished to hear - but for this reason the doors were shut against strangers.

/27v/ Tuesday $30^{\text {th }}$.

Went to Andral's ward, \& afterwards to Breschet's at the Hotel Dieu. Nothing particular in either. At Sichel's, some very good cases. Saw him remove with a knife a large Staphyloma of the Cornea with an Adherent Iris, produced by Ophthalmia Neonatorum. ${ }^{120}$ There was a very interesting case there - the man $c^{\text {ld }}$. see very well with each eye separately, but not with both together. ${ }^{121}$ Entered today a course of Dental Surgery ${ }^{122}-10$ francs - he Mr. Lemaire $^{123}$ is a miserable lecturer, but I think probably, a good many practical remarks may be gained from him - he told us today, that the primary may be distinguished from the secondary teeth by there being striae on the latter, whilst the former are entirely smooth. He

\footnotetext{
${ }^{116}$ Adherent Iris: Cooper in his section on the iris refers frequently to the work of Antonio Scarpa, Principali malattie degli occhi, Venice, 1802. The condition of adherent iris sometimes follows that of prolapse of the iris, sometimes called staphyloma of the iris, when part of it extrudes through a hole in the eyeball (caused by a wound or an ulcer) and through which some of the aqueous humour has escaped. Depending on the nature of recovery in the eye, it was likely, according to Scarpa, that some portion of the iris would remain adhered to the cornea, the membrane adjacent to the iris. (Dictionary of practical surgery, pp. 717-21.)

${ }^{117}$ Strumous ophthalmia was a condition resembling scrophulous ophthalmia. Conditions described as strumous indicated a scrofulous condition involving tumours of the glands associated with the lymphatic system and especially in the neck and behind the ears. Mild cases mainly affected young people but more virulent cases could involve the joints and, if not checked, lead to bone disease and muscle wasting. The eyes as in this case - could also be affected and develop ophthalmia, which could lead to opacity of the transparent cornea. The condition, although chronic, was not seen as contagious, but Hooper opines that it could be inherited. Treatments included a range of tonics, stimulants and narcotics of which hemlock was preferred, together with antiphlogistics. (Lexicon, p. 1106.)

${ }^{118}$ The Institute of France accommodated the Académie des Sciences, the premier scientific society of France. See Introduction, p. 10.

${ }^{119}$ Éloge historique de G. Cuvier, by M. Flourens, Secrétaire Perpétuel. This oration, published in 1834 two years after Cuvier's death in 1832, was included with details of Cuvier's published work and comments and reports on him by significant individuals in the scientific world. (Institut Royal de France, Académie Royale des Sciences, no. 4, Paris, 1831-36.)

${ }^{120}$ Ophthalmia neonatorum: inflammation of the eye especially where the conjunctiva was involved. In this case the condition was in a newborn infant and could have been gonorrhoeal in origin.

${ }^{121}$ See W. C. Wells, Two essays: one upon single vision with two eyes; the other on dew, 1818.

${ }^{122}$ This would have been a private course on dental surgery. The American Jonathan M. Warren describes his experience with toothache in Paris the previous year, when he was treated by M. Chevalier, whom he describes as "the first dentist here". (Parisian education, p. 162.) Since Warren had two teeth which needed to be extracted, it would seem that his dental treatment in North America may not have been of high quality. In Fabre, Dictionnaire des dictionnaires de médecine français et étrangers, vol. 3, pp. 262-79, there is an extensive entry on teeth indicating a sophisticated level of knowledge on structure and tooth care, as well as details about fillings, crowns and dentures.

${ }^{123}$ A dentist named Lemaire was listed in Almanach général, 1842, p. 518.
} 


\section{0-31 December 1834}

taught us to draw the front teeth of the upper jaw today with straight forceps. His method of fixing the head was very good - he stood on the right side of the patient, sitting in a chair he passed his left arm around the neck of the pat ${ }^{t}$. keeping the back head back against his chest. With the index \& middle fingers of the left hand the under jaw was pressed down \& the inferior teeth guarded - the upper lip was pressed up by the thumb - the forceps in the right hand were made to embrace the tooth $-\&$ the latter was bent or rather moved in four directions - from before backwards - from behind forwards - rotation \& traction downwards. With the Bicuspid - no rotation is necessary. In drawing the molar teeth he employs a very good plan of fixing the head - viz - to rest the thigh on the chair \& press firmly the head against it. ${ }^{124}$ After the lecture, he had in some patients, on whom he operated - \& I was remarkably struck with his dexterity - removing several teeth, whilst a general practitioner $/ 28 \mathrm{r} / \mathrm{w}^{\text {ld }}$. be thinking of it - for teeth of the under jaw he used an inst ${ }^{t}$. which I never remember to have seen before - possessing very considerable power as a lever, yet not like the key, making the gum a point of support. I think it likely to be a very instructive class. Vose left this afternoon - I am very extremely sorry for it - it is impossible to be in his company without learning something from him.

\section{Wednesday $31^{\text {st }}$.}

Went to the H. $S^{t}$. Louis this morning, not any new cases. I find that every visit to this Hosp'. makes one more expert at naming skin diseases. Saw some very good cases of Scrophula \& Syphilis in Alibert's wards - \& a case of Psoriasis Diffusa over the whole body in Biett's Salle, ${ }^{125}$ getting rapidly well under a milk diet alone without baths or any other treatment. There was a P.M. Examination today of a person who died of Apoplexy - considerable effusion of blood into the left ventricle ${ }^{126}$ with softening of the cerebral substance - the heart of the usual size, but the left ventricle in a state of concentric hypertrophy ${ }^{127}$ - valves healthy. At Sichel's there were some interesting cases - one of palsy ${ }^{128}$ of all the muscles supplied by the $3^{\text {rd }}$. pair of nerves. It was of several year's standing, \& appears to have arisen from disordered stomach in the first place. Another of dark colouring of the posterior layer of the capsule - another of deep seated cataract \&c. Went to the Tuilleries today ${ }^{129}-$ the

\footnotetext{
${ }^{124}$ Clearly the degree and nature of bodily contact between dentist and patient and the pressure the dentist could apply to the patient's body was then less regulated and seemingly tolerated.

${ }^{125}$ Salle: this is probably a reference to Biett's ward in the St. Louis hospital. Whilst most often used in reference to wards, salle could also be used for any large demonstration area in hospitals.

${ }^{126}$ Ventricle: term applied to fluid filled spaces in both the heart and the brain. In this case of stroke it refers to the brain.

${ }^{127}$ Hypertrophy refers to enlargement of the left ventricle of the heart.

${ }^{128}$ Palsy: paralysis, in this case involving the third or oculomotor cranial nerve innervating four of the external eye muscles.

${ }^{129}$ The palace of the Tuileries was begun by Catherine de' Medici in 1564, but work ceased on the prediction of an astrologer that the name St. Germain - that of the parish where the building was located - would be fatal to her. Subsequent monarchs added to and modified the building. Louis XIII lived there, as did Louis XIV until he built Versailles. It was subsequently used as the seat of government until Napoleon took it over. Pope Pius VII lived there from 1804 until the brief restoration of the monarchy when Louis XVIII took up residence. Visitors were allowed to view the interior of the palace with its collections of paintings, sculpture and furniture and could be admitted to the chapel (but have no view of the royal family) on application for a ticket in summer or at other times when the royal family were in the country. However, "If our tourist be in full dress, he may obtain a seat in a gallery on a line with that of the royal family; but if he wears either boots or loose pantaloons, he will in vain apply for admittance". (Galignani's new Paris guide, pp. 149-60.)
} 


\section{December 1834}

bands of all the regiments in Paris were drawn up in front of the Palais, \& played various tunes alternately, 12 bands, - nearly 400 drums once struck up alone without any other accompaniment - a most dismal noise they made as far removed from music as a donkey's Bray. Altogether I did not think any of the tunes so good as the martial music of Old England $^{130}$ - I was quite disappointed. Have been reading Gibert's Manuel of Diseases of the Skin. ${ }^{131}$ I like it much, it is not so dry \& uninteresting as most of such works. Sichel told us a few days since, that tho' astringents ${ }^{132} \&$ stimulants $^{133}$ are good in conjunctivitis, yet, when the tarsal ${ }^{134}$ cartilages are inflamed, they do considerable harm.

${ }^{130}$ Old England: slang term for the "old country" as distinguished from New England in North America. Whilst it would not be surprising if, in his homesick condition, he had made the remark about a similar display of music from the American students in Paris, his use of the term vis-à-vis the French is more unusual.

${ }^{131}$ It is likely that he was reading the French edition: C. M. Gibert, Manuel des maladies spéciales de la peau, 1834. An English edition of this date has not been traced.

${ }_{132}$ Astringents were substances which were held to firm up parts of the body and to diminish excessive discharges. They included acids, alum, lime-water, chalk, certain preparations of copper, zinc, iron and lead. (Hooper, Lexicon, p. 196.)

${ }^{133}$ Stimulants were substances believed to possess the power of exciting the animal energy. They were grouped under three headings: tonics such as cantharides; diffusibles such as alkali volatile, electricity and heat; cordials such as cinnamomum and wine. (Hooper, Lexicon, p. 1158.) Alkali volatile is more commonly known as ammonia and cinnamomum is familiar as cinnamon.

${ }^{134} \mathrm{~A}$ tarsus is the thin cartilage situated at the edges of the eyelids to preserve their firmness and shape. 